Supporting Information for

\title{
Overcoming the Trade-Off between Water Permeation and Mechanical Strength of Ceramic Membrane Supports by Interfacial Engineering
}

Qilin $G U^{a,{ }^{*},}$ Masashi KOTOBUKI ${ }^{a}$, Chin Ho KIRK ${ }^{a}$, Meibo HE ${ }^{b}$, Gwendolyn J.H. $\operatorname{LIM}^{a}$, Tze Chiang Albert $N G^{b}$, Lei ZHANG ${ }^{a}$, How Yong $N G^{b, c,{ }^{*}, \text { John } W A N G}{ }^{a,{ }^{*}}$

${ }^{a}$ Department of Material Science and Engineering, Faculty of Engineering, National University of Singapore, 117574, Singapore

${ }^{b}$ Centre for Water Research, Department of Civil and Environmental Engineering, National University of Singapore, 1 Engineering Drive 2, Singapore 117576

c NUS Environmental Research Institute, National University of Singapore, $5 \mathrm{~A}$ Engineering Drive 1, 117411, Singapore

${ }^{*}$ Corresponding authors: Qilin Gu (msegq@nus.edu.sg); How Yong Ng (howyongng@nus.edu.sg);John Wang (msewangj@nus.edu.sg)

Submitted to ACS Applied Materials \& Interfaces 

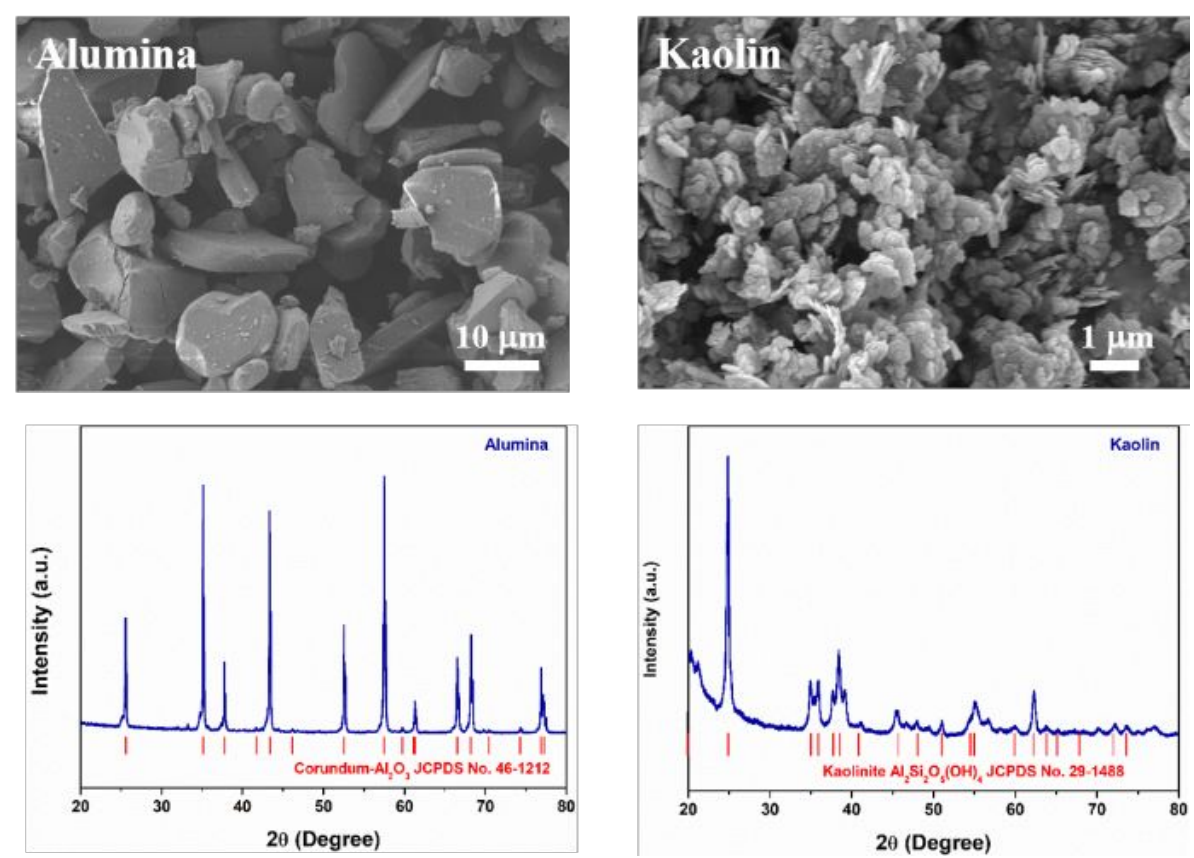

Figure S1. SEM images and XRD patterns of raw materials: alumina powder and kaolin powders.

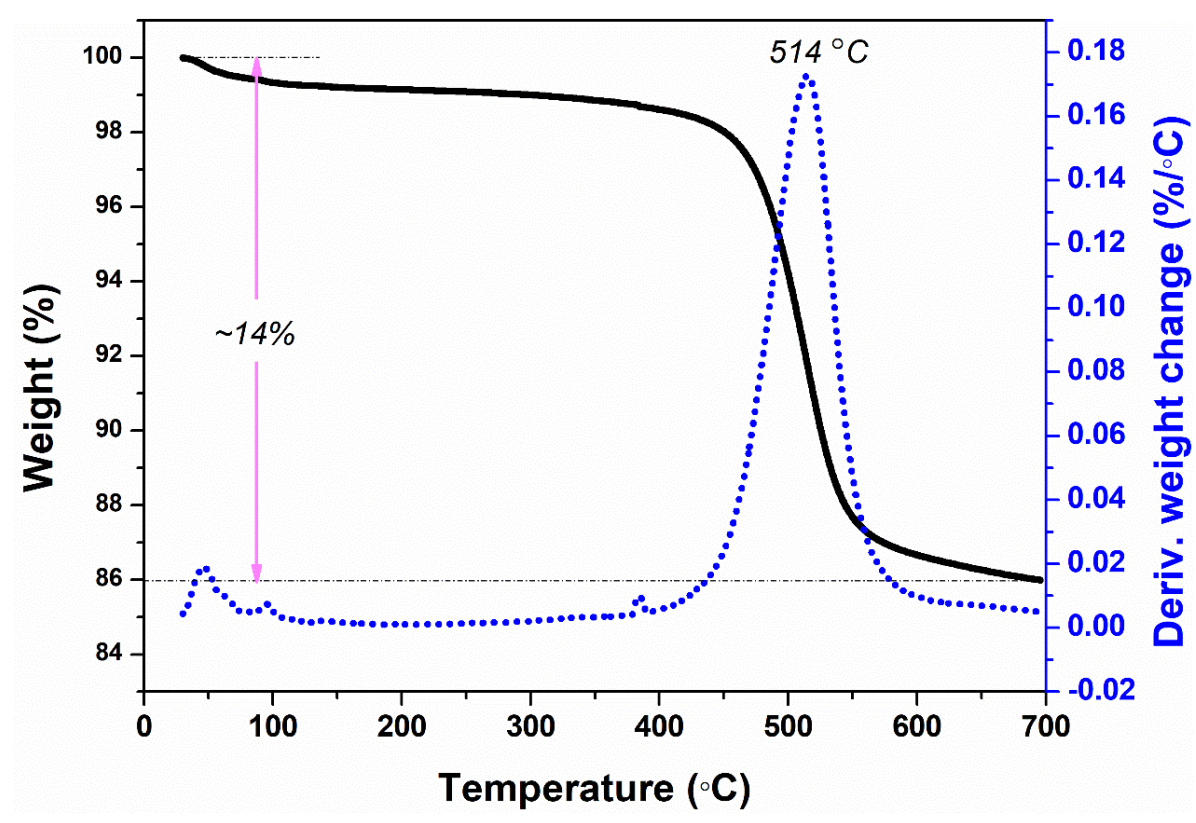

Figure S2. TGA curve of kaolin nanoflakes in air with a ramping rate of $10{ }^{\circ} \mathrm{C} / \mathrm{min}$. 


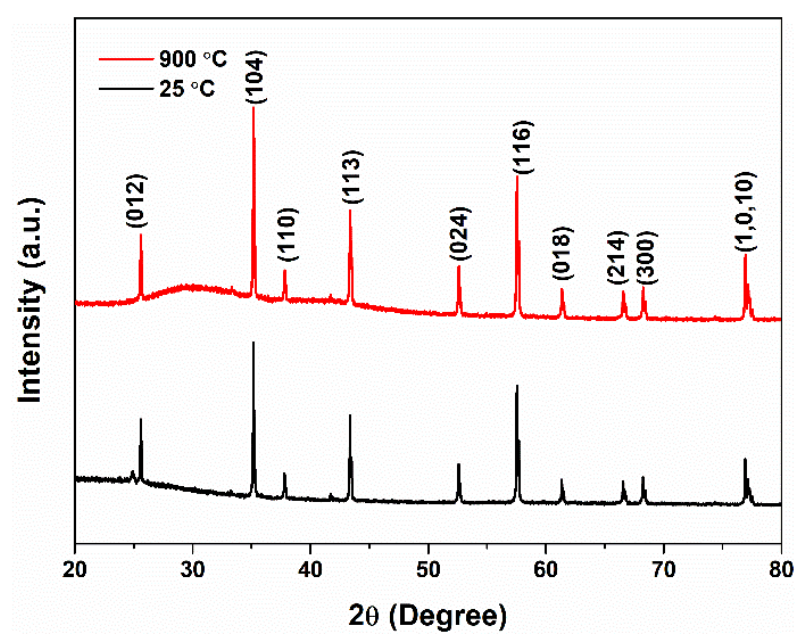

Figure S3. XRD patterns of extruded samples before and after thermal analysis. 


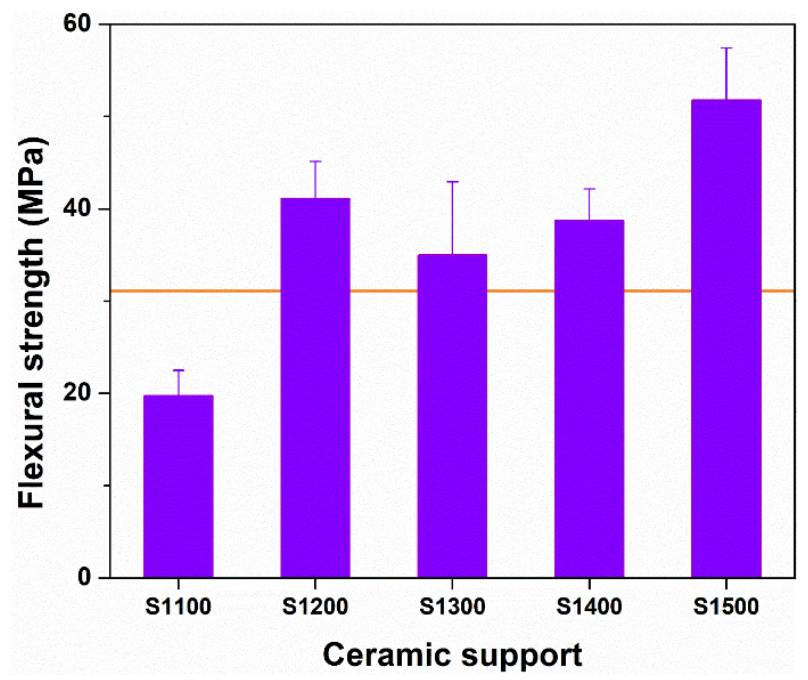

Figure S4. Flexural strength of ceramic supports parallel to the channels. 


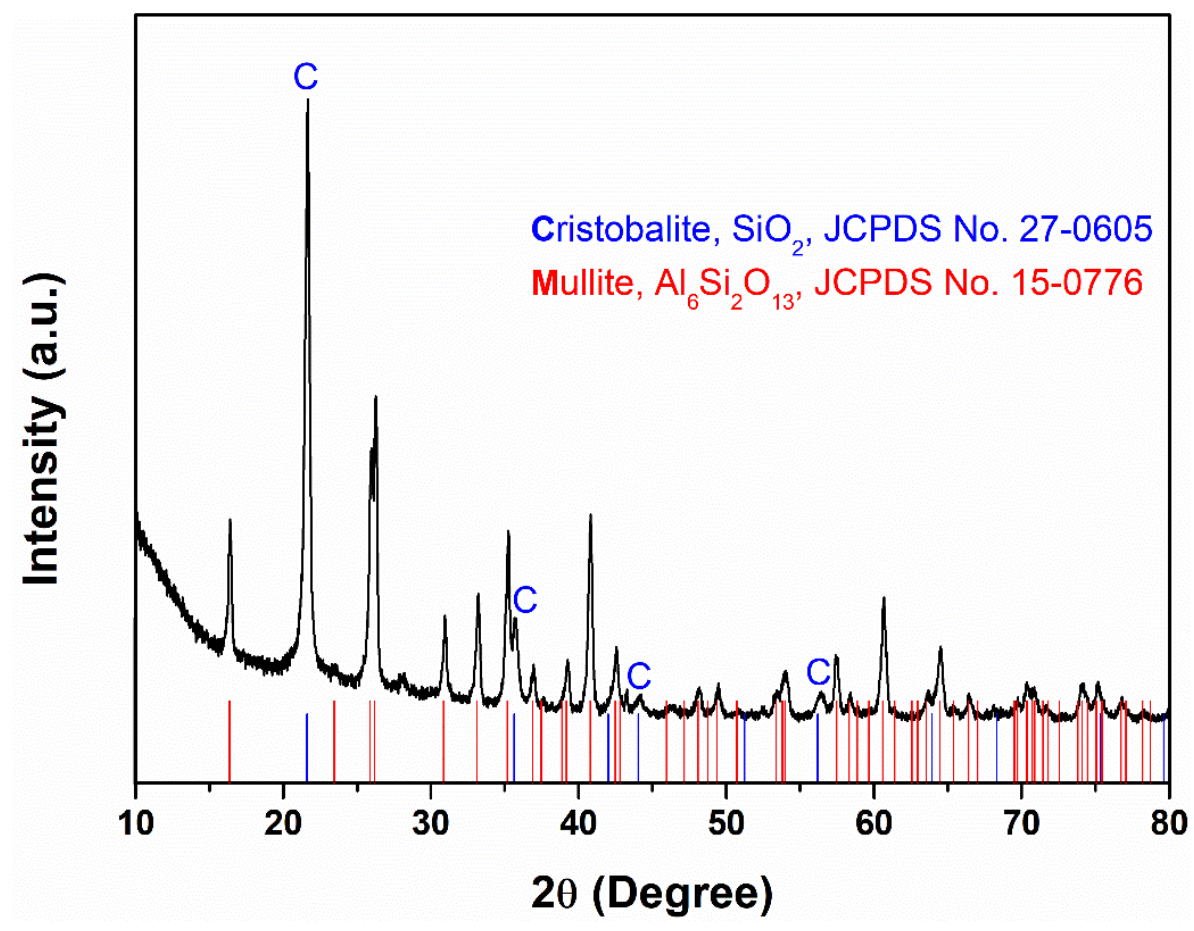

Figure S5. XRD patterns of kaolin flakes after treated at $1400{ }^{\circ} \mathrm{C}$ for $2 \mathrm{~h}$.

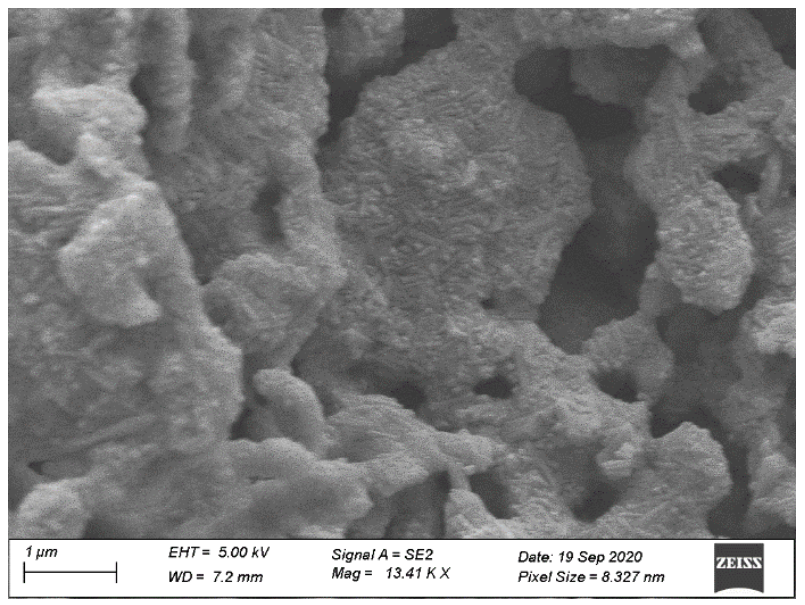

Figure S6. SEM image of kaolin flakes after treated at $1400{ }^{\circ} \mathrm{C}$ for $2 \mathrm{~h}$. 


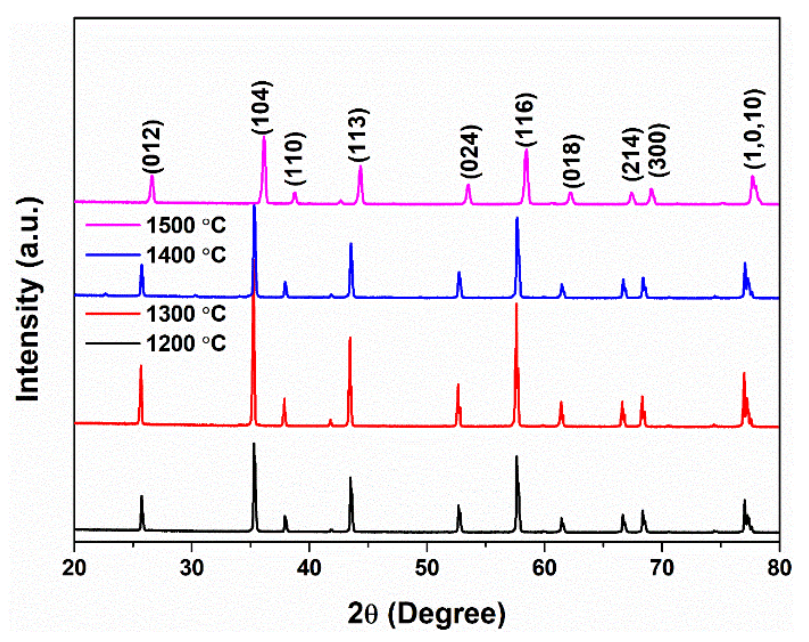

Figure S7. XRD patterns of ceramic supports prepared at various temperatures.

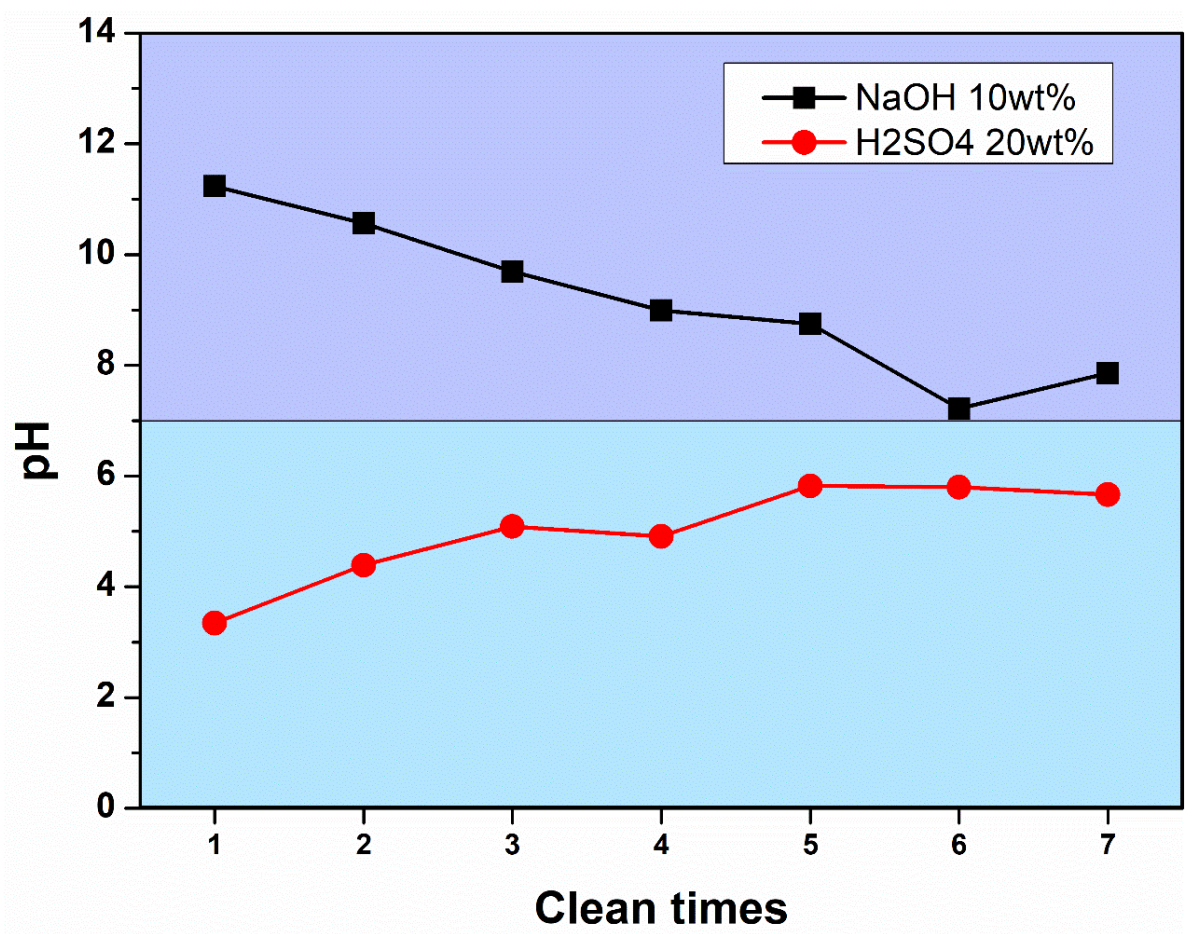

Figure S8. The pH values of the solution during the cleaning of corroded ceramic supports. 

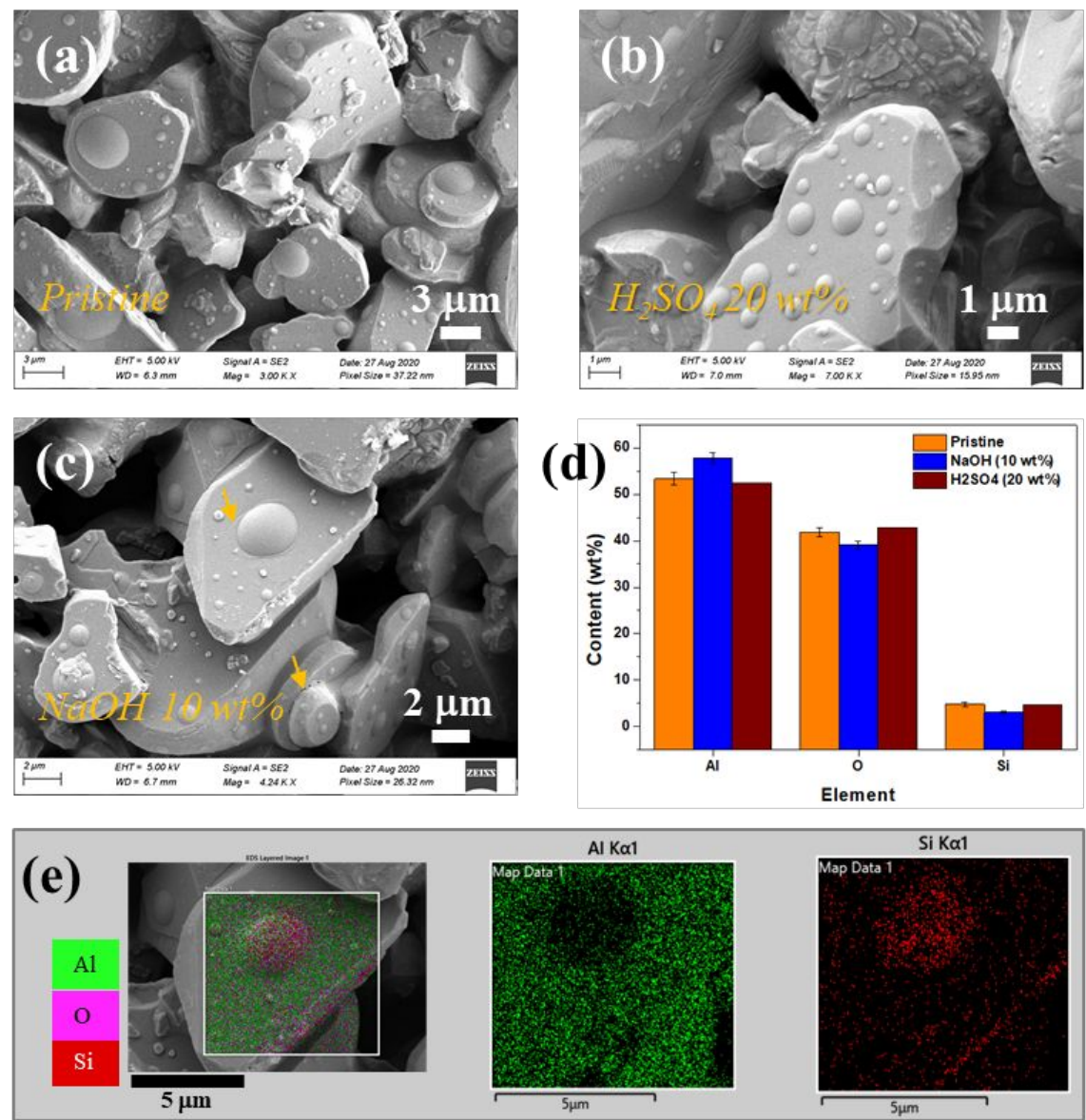

Figure S9. Microstructure and chemical composition of ceramic supports after corrosion treatment. Surface SEM images of (a) pristine ceramic support, and that after corrosion treatment in (b) $20 \mathrm{wt} \% \mathrm{H}_{2} \mathrm{SO}_{4}$ and (c) $10 \mathrm{wt} \% \mathrm{NaOH}$. (d) Relative contents of chemical composition before and after corrosion treatment. (e) Elemental distribution of the selected area in (c).

The surface microstructure and chemical composition of the samples after corrosion treatment are also examined. Both the samples in $\mathrm{H}_{2} \mathrm{SO}_{4} 20 \mathrm{wt} \%$ and $\mathrm{NaOH} 10 \mathrm{wt} \%$ retain similar surface features to that of the pristine (Figures S9a-c). Compositional analysis results (Figure S9d) show that the Si content in the samples treated in $\mathrm{NaOH} 10 \mathrm{wt} \%$ was slightly reduced, suggesting that weak corrosion occurs on the surface, as evidenced by the rings and holes surrounding the drop-like 
humps (Figure S9c). However, the drop-like humps are still abundant in Si element (Figure S9e).
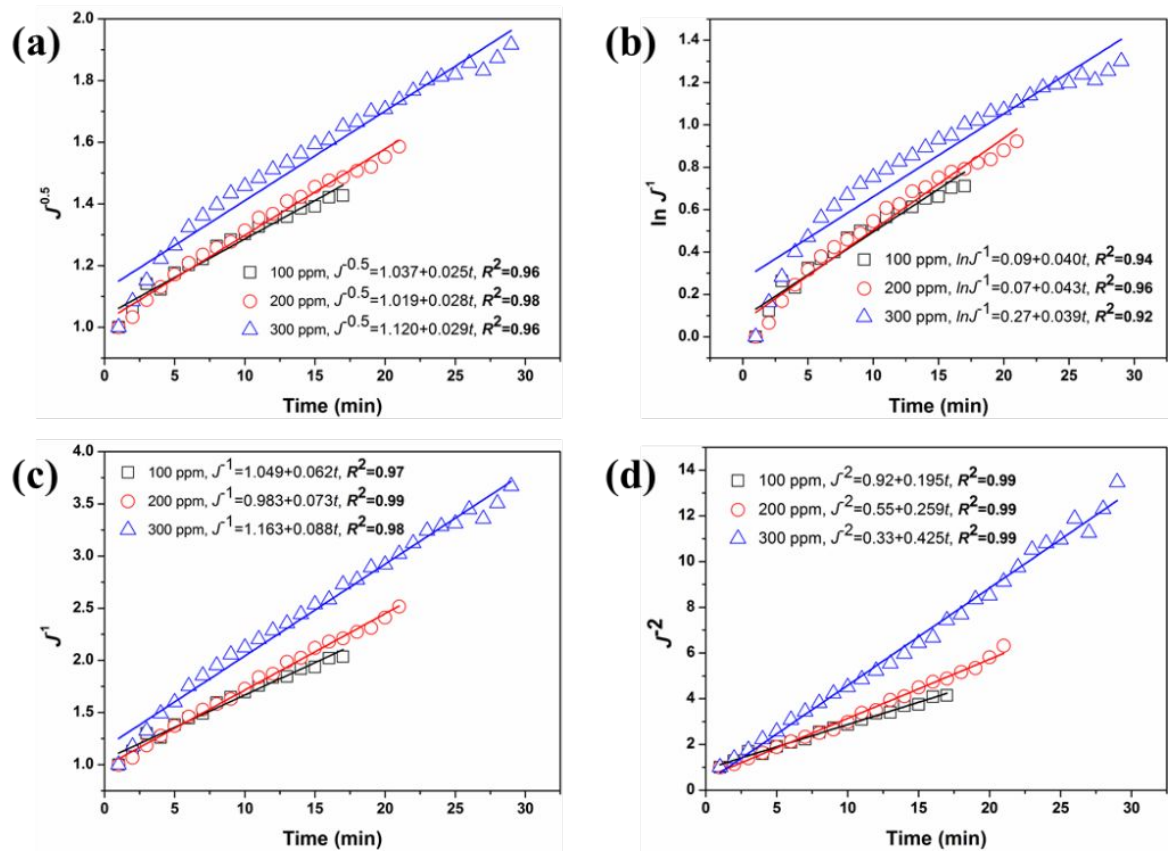

Figure S10. Fitting results of the normalized flux using four classical models. (a) Standard pore blocking model, (b) complete pore blocking model, (c) intermediate pore blocking model, and (d) cake filtration model.

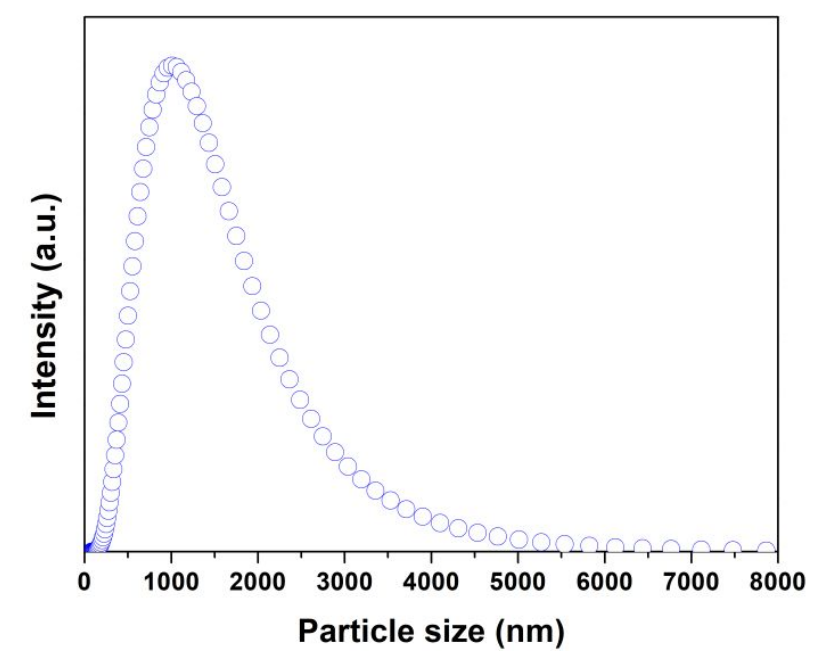

Figure S11. Size distribution of the oil droplets in the oily wastewater (100 ppm). 
Table S1. Summary of the pure water flux at 1 bar and the pure water permeance of ceramic supports prepared at different temperatures.

\begin{tabular}{ccc}
\hline $\mathrm{T} /{ }^{\circ} \mathrm{C}$ & Permeance/LMHB & Flux@1bar/LMH \\
\hline 1200 & $6808.59 \pm 368.31$ & $7361.96 \pm 79.49$ \\
1300 & $7831.07 \pm 137.67$ & $7479.48 \pm 86.93$ \\
1400 & $9911.88 \pm 357.51$ & $8969.52 \pm 138.09$ \\
1500 & $4975.73 \pm 164.23$ & $4882.70 \pm 156.14$ \\
\hline
\end{tabular}

